\title{
Fear and Courage in Children: Two Sides of the Same Coin?
}

\author{
Peter Muris
}

Published online: 26 March 2009

(C) The Author(s) 2009. This article is published with open access at Springerlink.com

\begin{abstract}
This study further investigated the construct of courage in children. Children aged $8-13$ years $(n=51)$ were interviewed about the most courageous action that they had ever performed during their life, and to retrospectively rate their level of fear and courage experienced during that event. On a separate occasion, children also completed the Courage Measure for Children (CM-C) as an index of children's general level of personal courage, as well as scales for assessing anxiety symptoms and sensation seeking. Results indicated that almost all children (i.e., 94\%) indicated that they had carried out a courageous action at some point during their life, although the levels of fear and courage associated with these acts varied considerably. Further, there was no relation between fear and courage reported for the courageous action, but these variables were significantly correlated with respectively anxiety symptoms and personal courage as indexed by the CM-C. Finally, a significant positive correlation was observed between sensation seeking and personal courage, indicating that children who are more thrill and adventure seeking are generally also more courageous. It is concluded that fear and courage in children are largely unrelated and not just two sides of the same coin. The implications of these results for the etiology and treatment of childhood anxiety problems are discussed.
\end{abstract}

Keywords Fear $\cdot$ Courage $\cdot$ Anxiety $\cdot$ Sensation seeking · Children

P. Muris $(\square)$

Institute of Psychology, Erasmus University Rotterdam, P.O. Box 1738, 3000 DR Rotterdam, The Netherlands

e-mail: muris@fsw.eur.nl

\section{Introduction}

Courage has been defined by Rachman $(1984,2004)$ as 'behavioral approach in spite of the experience of fear', and this definition has been mainly based on studies of paratrooper soldiers who were closely followed during their military training program (Cox et al. 1983; McMillan and Rachman 1988; O'Connor et al. 1985). Some of the paratroopers were defined as fearful: i.e., these soldiers showed high levels of physiological arousal and failed to perform their jump. In contrast, there were paratroopers who exhibited no noteworthy arousal and smoothly carried out the jump. Most importantly, there was also a group of paratroopers who displayed similar high levels of arousal as the fearful group, but nevertheless successfully completed the jump. These 'courageous' paratrooper soldiers performed the same action as their fearless colleagues in spite of experiencing fear.

Rachman's (1984, 2004) conceptualization of courage as approach behavior in combination with fear seems also relevant to clinical psychology, and in particular to the domain of fear, anxiety and their disorders. To begin with, according to learning theory, courage might interfere with the development of pathological fear and anxiety. More precisely, when facing threat, those who engage in courageous behavior by exposing themselves to the feared stimulus or situation, are less likely to develop serious anxiety problems. In contrast, those who display a tendency to avoid and act cowardly will show a continuation and exacerbation of their fears (Mowrer 1960). In a similar vein, courage may also play a role during the treatment of anxiety disorders. Behavior therapy, which is currently viewed as the most effective intervention for these problems (Barlow 2002), considers exposure to the feared stimulus or situation as a crucial element (e.g., Marks 
1987). It seems plausible to assume that more courageous patients who closely adhere to the exposure exercises will profit more from this type of treatment than patients who display a tendency to quickly withdraw from such exercises (see Rachman 2004).

Given the relevance of courage within the context of fear and anxiety, and acknowledging the fact that many anxiety problems already tend to arise at a fairly young age (Craske 2003; Muris 2007), it seems worthwhile to explore this concept in young people. A recent study by Muris et al. (2009) made a first attempt to address this issue. Children aged 9-13 years were interviewed about their personal courageous actions. In addition, children completed a set of questionnaires in order to investigate the personality and psychopathology correlates of courage. The results indicated that the majority of children were familiar with the concept of courage as they reported to have performed a courageous action during their life. Further, it was found that children's courage scores were positively related to the Big Five personality traits of extraversion and a masculine sex role, whereas a small but significant negative correlation was observed with anxiety symptoms.

The latter finding is interesting from a clinical psychology perspective, as it seems to support the notion that courageous children are less prone to develop chronic anxiety symptoms. In the meantime, Rachman's (2004) notion that courageous behavior is conducted in spite of fear implies that fear and courage should be largely independent. The Muris et al. (2009) study only addressed the correlation between children's courage and general levels of anxiety symptoms, and thus remains silent about the link between courage and fear in a specific situation. As it may well be that children are less able to differentiate these concepts, the possibility cannot be ruled out that in this population fear and courage are just two sides of the same coin. The present study was set-up to further explore this issue. School children aged 8-13 years were asked to complete a set of questionnaires containing a scale for measuring individual differences in courage and a measure of anxiety symptoms. In addition, children were interviewed about the most courageous action ever performed during their life, and for this event they were also asked to report levels of situational fear and courage. In keeping with Muris et al. (2009) we expected to find at best a small negative association between children's general level of courage and anxiety symptoms, whereas there should be no substantial link between situational courage and fear. Further, we investigated whether individual differences in courage were significantly related to situational courage scores, which of course would provide some support for the idea that courage has trait-like properties and has an effect on children's evaluations of their own behavior in a challenging situation. Finally, in the current study, we also included a measure of sensation seeking in order to examine its relationship to individual differences in courage. Based on Zuckerman's (1994) theory, it can be predicted that sensation seeking is positively linked to children's courage as this basic personality trait is characterized by a tendency to actively seek for thrilling and adventurous events.

\section{Methods}

\section{Participants}

Fifty-one children (18 boys and 33 girls) of a regular primary school were recruited for the purpose of the present study. Children had a mean age of 10.80 years $(S D=0.72$; range 9-12 years). No exact information on the socio-economic background of the children was available, but it can be mentioned that $66.7 \%$ of them was from original Dutch descent. The other $33.3 \%$ had an ethnic minority background (e.g., Surinam, Cape Verdean, Turkish, Moroccan, or Eastern European), which in the Netherlands often is indicative for a lower socio-economic status.

\section{Questionnaires}

The Courage Measure for Children (CM-C) is an agedownward version of the self-report scale of courage that was recently developed by Norton and Weiss (2009). The measure consists of 12 items (e.g., "I try to get over my fears", "I behave myself in a brave way", "If I am anxious about something, I will do or face it anyway", and "If something scares me, I try to get away from it" [reverse item]) that have to be rated on a four-point Likert scale $(1=$ not true, $2=$ somewhat true, $3=$ true, and $4=$ very true). After recoding reverse items, a total courage score can be computed with higher scores being indicative of higher levels of courageous behavior. The previous study by Muris et al. (2009) demonstrated that the CM-C is reliable in terms of internal consistency (with Cronbach's alphas in the $0.70-0.80$ range), and possesses adequate validity as shown by positive correlations with a parentrated version of the scale $(r=0.45)$ and an alternative index of self-reported childhood courage $(r=0.46)$.

The Screen for Child Anxiety Related Emotional Disorders (SCARED) is a self-report questionnaire for measuring anxiety symptoms in children and adolescents (Birmaher et al. 1999). The scale consists of 41 items that can be allocated to five subscales: panic/somatic (e.g., "When frightened, my heart beats fast"), generalized anxiety (e.g., "I am a worrier"), separation anxiety (e.g., "I don't like being away from my family"), social phobia (e.g., "I don't like to be with unfamiliar people"), and 
school phobia (e.g., "I am scared to go to school"). Children are asked to rate the frequency with which they experience each symptom using three-point scales $(0=$ almost never, $1=$ sometimes, and $2=$ often $) . \mathrm{A}$ SCARED total score was obtained by summing across all items. Research has demonstrated that the SCARED has good internal consistency, test-retest reliability, and validity, and this conclusion appears true for clinical as well as non-clinical samples of youths (Birmaher et al. 1999; Muris et al. 2002).

The thrill and adventure seeking subscale version of the Sensation Seeking Scale for Children (SSSC; Russo et al. 1993) consists of 10 items that refer to the tendency to engage in physically risky activities such as skiing, parachuting, and mountain climbing. Each item had to be answered on a five-point scale with $1=$ not true to $5=$ very true. A total SSSC score can be computed by summing responses to all items. Previous studies have shown that the SSSC is a reliable and valid measure of sensation seeking in youths (Russo et al. 1991, 1993).

\section{Courage Interview}

During the interview, children were first asked whether they knew what 'courage' is. Next, all children were provided with the following definition "Courage is that you dare to do something in spite of the fact that you are scared", after which they were invited to report on the most courageous action that they had performed during their life: "What can you tell me about this situation and your courageous behavior?", and to rate retrospectively on two separate Likert scales how much fear they had experienced at that time (i.e., situational fear; $1=$ no fear at all, $9=a$ lot of fear) and how courageous they found their act (i.e., situational courage; $1=$ not at all courageous, $9=$ very courageous).
Procedure

Parents first received information about the study along with a consent form. The participation rate was reasonable: about half of the parents who were approached, eventually gave permission for their child to participate in the study. Upon agreement of parents, children completed a set of questionnaires. This was done in classroom sessions during which a research assistant and the teacher were always present in order to ensure confidential and independent responding. Within 2-4 weeks after the classical assessment, the courage interview was conducted for each individual child. The interview was administered at school in a separate room by the same research assistant who was for that matter still blind to children's questionnaire scores.

\section{Results}

\section{General Findings}

Children appeared to understand the meaning of the concept of courage. With few exceptions, they indicated that courage implies that "You dare to do something" or "You do something scary". The vast majority (i.e., 94.1\%) also reported to have performed a personal courageous action at some point during their life. As can be seen in Table 1, the most prevalent courageous acts were concerned with performing a physically risky action $(33.3 \%)$, going in a roller coaster $(18.8 \%)$, and dealing with a feared animal $(12.5 \%)$.

Descriptive statistics of various questionnaires and scales are displayed in Table 2. Note that the CM-C was found to be a reliable index for measuring individual differences in children's courage, with a Cronbach's alpha of 0.73. Other questionnaires also displayed satisfactory internal consistency (with alphas $>0.80$ ). There were no

Table 1 Types of courageous actions reported by the children during the courage interview (CI)

\begin{tabular}{llll}
\hline & Type of action & $n(\%)$ & Sample narrative \\
\hline 1. & Performing a physically risky action & $16(33.3)$ & I made a somersault from the diving board \\
2. & Going in a roller coaster & $9(18.8)$ & In a amusement park, I went in 'the Python' and made several loopings \\
3. & Dealing with a feared animal & $6(12.5)$ & I am scared of mice, but I dared to stroke the pet mouse of my friend \\
4. & Dealing with dangerous environment & $4(8.3)$ & I crossed a deep canyon on a narrow iron bridge \\
& Doing scary things in the dark & $4(8.3)$ & The light in the cellar was broken, but I went in to get something for my mother \\
5. & Dealing with a scary person & $2(5.0)$ & I had to pick up my ball from the garden of an old scary woman \\
& Enduring a medical procedure & $2(5.0)$ & My shoulder was dislocated and the doctor had to place it back \\
& Helping another person & $2(5.0)$ & I defended my friend who was bullied by an older boy \\
6. Performing in public & $2(5.0)$ & I had to sing on my birthday in front of friends and family \\
\hline
\end{tabular}

Percentages are calculated on the basis of the sample of children who reported a courageous action $(n=48)$. Three children did not report an act of courage 
Table 2 Descriptive statistics for questionnaires/scales employed in this study as well as Pearson product-moment correlations among these variables

\begin{tabular}{|c|c|c|c|c|c|c|c|}
\hline & $M(\mathrm{SD})$ & Range & $\alpha$ & (1) & (2) & (3) & (4) \\
\hline 1. CM-C personal courage & $31.14(4.84)$ & $23-46$ & 0.73 & & & & \\
\hline 2. SCARED anxiety symptoms & $23.51(9.81)$ & $5-47$ & 0.87 & $-0.27 *$ & & & \\
\hline 3. SSSC sensation seeking & $26.86(8.76)$ & $13-44$ & 0.84 & $0.63 * * *$ & -0.07 & & \\
\hline 4. CI situational fear & $5.88(1.44)$ & $3-9$ & - & $-0.30 * *$ & $0.31 * *$ & -0.09 & \\
\hline 5. CI situational courage & $5.50(1.82)$ & $1-9$ & - & $0.31 * *$ & 0.02 & 0.13 & 0.08 \\
\hline
\end{tabular}

For the CI scores, no reliability coefficients could be calculated as these consisted of a single item

CM-C Courage Measure for Children, SCARED Screen for Child Anxiety Related Emotional Disorders, SSSC Sensation Seeking Scale for Children, $C I$ courage interview

$* p<0.10$, ** $p<0.05$, *** $p<0.001$

significant gender differences for any of the main constructs that were assessed in this study [all $t(49)$ 's $<1.20$, $p$ 's $>0.25]$.

Relations Between Courage, Fear/Anxiety, and Sensation Seeking

Correlations between various measures are shown in the right panel of Table 2. As can be seen, general levels of courage as measured by means of the CM-C were weakly but negatively related to anxiety symptoms as indexed by the SCARED total score $(r=-0.27, p<0.10)$. Additional correlations computed between the CM-C and SCARED subscales revealed that personal courage did show significant negative correlations to symptoms of separation anxiety $(r=-0.31, p<0.05)$ and social phobia $(r=-0.37, p<0.01)$. Obviously, these findings indicate that higher levels of personal courage are to some extent associated with lower levels of anxiety symptoms. Note also that the correlation between situational fear and courage was clearly non-significant, $r=0.08$, which indicates that these concepts were not related to each other.

As predicted, there was a significant positive relationship between personal courage and the level of situational courage as reported by children for their most brave action ever performed $(r=0.31, p<0.05)$. Further, anxiety symptoms were positively associated with situational fear $(r=0.31, p<0.05)$, which indicated that children who were generally anxious also rated higher fear levels for their idiosyncratic courageous event. Personal courage was negatively linked to situational fear $(r=-0.30, p<0.05)$, although it should be mentioned that this relation was no longer significant when controlling for anxiety symptoms $(r=-0.15, \mathrm{~ns})$.

Finally, CM-C scores were substantially and positively related to sensation seeking as measured by the thrill and adventure seeking subscale of the SSSC $(r=0.63$, $p<0.001)$. Thus, higher levels of personal courage were accompanied by higher levels of sensation seeking.

\section{Discussion}

The present study again demonstrates that children aged 9-12 years appear to comprehend the concept of courage (see also Muris et al. 2009). That is, the vast majority of them was able to provide a meaningful description of the construct, and reported that they had performed a courageous action at some point during their life. In general, the types of courageous acts mentioned (e.g., performing a physically risky action, going in a roller coaster, dealing with a feared animal) were highly similar to those reported by children and adults in previous research (Muris et al. 2009; Pury et al. 2007).

Personal courage was negatively associated with children's general levels of anxiety symptoms, especially in situations involving separation from caregivers and social encounters with other people. Obviously, this result is in keeping with the idea that habitually courageous children are less prone to develop anxiety problems, because they are likely to expose themselves to challenging events even though they may temporarily experience some fear in such situations. The fact that personal courage was predominantly (negatively) linked to symptoms of social phobia and separation anxiety (and not to other anxiety symptoms) may have to do with the fact that events referring to these types of anxiety symptoms regularly occur at this age, and thus may be particularly relevant to the children who participated in this study.

While personal courage and general anxiety symptoms were at least to some extent negatively associated, there was absolutely no meaningful link between situational courage and fear as scored by the children for their idiosyncratic courageous action. This means that children with low levels of fear were not the most brave and vice versa that children with high levels of fear were not faint-hearted, but rather that fear and courage as assessed within a challenging situation are relatively independent constructs and not just two sides of the same coin. The latter finding is in line with Rachman's (1984, 2004) notion that courageous behavior 
can be conducted in spite of fear, and justifies further research on courage as a potentially protective mechanism in children who are exposed to frightening situations.

Individual differences in courage were positively related to situational courage as reported by the children for their most brave action, which at least indicates that courage has trait-like properties. Critics may argue that the correlation between personal and situational courage was quite modest ( $r=0.31$ ), but this can be countered by pointing out that this is a common observation in research on personality characteristics, especially when behavior is assessed only once and hence the sampling error is large (Epstein 1979).

Sensation seeking was found to be a clear correlate of personal courage. More precisely, higher levels of this basic personality trait were accompanied by higher levels of courage. Of course, this finding makes sense from a theoretical point-of-view as sensation seeking can be defined as "a trait defined by the seeking of varied, complex, and intense sensations and experiences, and the willingness to take physical, social, legal, and financial risks for the sake of such experience" (Zuckerman 1994, p. 27). In particular, the element of 'willingness to take physical and social risks' nicely fits with the concept of courage, and as such not surprisingly also emerged as a prominent feature of children's self-reported courageous acts.

It should be acknowledged that the present study suffers from various limitations. A main shortcoming is that the study solely relied on children's self-report. The inclusion of parent report data would certainly have strengthened this research as this might have yielded important cross-validational information on children's personal and situational courage levels. Nevertheless, this research provided some interesting new information on the concept of courage in children. Future studies should further explore whether personal courage is predictive of children's approach behavior in a standardized challenging situation (cf. Norton and Weiss 2009) or is associated with greater involvement in exposure exercises during behavior therapy for anxious youths (Hudson and Kendall 2002). Obviously, such evidence would confirm the notion that courage is a relevant clinical construct that might be involved in the development and treatment of anxiety problems in youths.

Open Access This article is distributed under the terms of the Creative Commons Attribution Noncommercial License which permits any noncommercial use, distribution, and reproduction in any medium, provided the original author(s) and source are credited.

\section{References}

Barlow, D. H. (2002). Anxiety and its disorders. The nature and treatment of anxiety and panic (2nd ed.). New York: Guilford.
Birmaher, B., Brent, D., Chiappetta, L., Bridge, J., Monga, S., \& Baugher, M. (1999). Psychometric properties of the Screen for Child Anxiety Related Emotional Disorders (SCARED): A replication study. Journal of the American Academy of Child and Adolescent Psychiatry, 38, 1230-1236. doi:10.1097/00004583199910000-00011.

Cox, D., Hallam, R. S., O'Connor, K., \& Rachman, S. J. (1983). An experimental analysis of fearfulness and courage. The British Journal of Psychology, 74, 107-117.

Craske, M. G. (2003). Origins of phobias and anxiety disorders. Why more women than men?. Oxford: Elsevier.

Epstein, S. (1979). The stability of behavior: I. On predicting most of the people much of the time. Journal of Personality and Social Psychology, 37, 1097-1126. doi:10.1037/0022-3514.37.7.1097.

Hudson, J., \& Kendall, P. C. (2002). Showing you can do it: Homework in therapy for children and adolescents with anxiety disorders. Journal of Clinical Psychology, 58, 525-534. doi:10.1002/jclp. 10030.

Marks, I. M. (1987). Fears, phobias, and rituals. Panic, anxiety, and their disorders. New York: Oxford University Press.

McMillan, T. M., \& Rachman, S. J. (1988). Fearlessness and courage in paratroopers undergoing training. Personality and Individual Differences, 9, 373-378. doi:10.1016/0191-8869(88)90100-6.

Mowrer, O. H. (1960). Learning theory and behavior. New York: Wiley.

Muris, P. (2007). Normal and abnormal fear and anxiety in children and adolescents. Oxford, UK: Elsevier.

Muris, P., Mayer, B., \& Schubert, T. (2009). "You might belong in Gryffindor": Children's courage and its relationships to anxiety symptoms, Big Five personality traits, and sex roles (submitted).

Muris, P., Merckelbach, H., Ollendick, T. H., King, N. J., \& Bogie, N. (2002). Three traditional and three new childhood anxiety questionnaires: Their reliability and validity in a normal adolescent sample. Behaviour Research and Therapy, 40, 753772. doi:10.1016/S0005-7967(01)00056-0.

Norton, P. J., \& Weiss, B. J. (2009). The role of courage on behavioral approach in a fear-eliciting situation: A proof-ofconcept pilot study. Journal of Anxiety Disorders, 23, 212-217. doi:10.1016/j.janxdis.2008.07.002.

O’Connor, K., Hallam, R. S., \& Rachman, S. J. (1985). Fearlessness and courage: A replication experiment. The British Journal of Psychology, 76, 187-197.

Pury, C. L. S., Kowalski, R. M., \& Spearman, J. (2007). Distinctions between general and personal courage. Journal of Positive Psychology, 2, 99-114. doi:10.1080/17439760701237962.

Rachman, S. J. (1984). Fear and courage. Behavior Therapy, 15, 109120. doi:10.1016/S0005-7894(84)80045-3.

Rachman, S. J. (2004). Fear and courage: A psychological perspective. Social Research, 71, 149-176.

Russo, M. F., Lahey, B. B., Christ, M. G., Frick, P. J., McBurnett, K., Walker, J. L., et al. (1991). Preliminary development of a sensation seeking scale for children. Personality and Individual Differences, 12, 399-405. doi:10.1016/0191-8869(91)90056-H.

Russo, M. F., Stokes, G. S., Lahey, B. B., Christ, M. G., McBurnett, K., Loeber, R., et al. (1993). A sensation seeking scale for children: Further refinement and psychometric development. Journal of Psychopathology and Behavioral Assessment, 15, 69-86. doi:10.1007/BF00960609.

Zuckerman, M. (1994). Behavioral expressions and biosocial bases of sensation seeking. Cambridge, England: Cambridge University Press. 